\title{
La cuaternidad de los estilos de aprendizaje y el código Phisca-tawa en el sistema educativo inca
}

\author{
CARLOS QUINTANILLA RAUCH ${ }^{*}$ \\ Universidad Peruana Los Andes - Perú \\ Recibido el 03-04-19; primera evaluación el 08-12-19; \\ segunda evaluación el 02-04-20; aceptado el 02-06-20
}

\section{RESUMEN}

La teoría educativa de los estilos de aprendizaje busca desarrollar un aprendizaje significativo en los estudiantes para alcanzar adecuadas competencias profesionales, siendo una visión pedagógica relevante en el campo educativo actual. Por otra parte, las investigaciones actuales están redescubriendo la cosmovisión de los incas, y permiten la teorización de un sistema de buen aprendizaje llamado en quechua allinta, basado en un código de principios valorativos que permitió formar especialistas en diversos campos del conocimiento, conocidos como kamayoq. Este estudio permite analizar el posible paralelismo de los estilos de aprendizaje actual con la ancestral cosmovisión educativa de los incas, porque a pesar de referirse a diferentes contextos educativos, permitieron el logro de las capacidades técnicas del kamayoq inca, similares a las competencias del profesional actual.

Palabras clave: estilos de aprendizaje, cosmovisión inca, código Phisca-tawa, sistema educativo inca.

\footnotetext{
* Licenciado en Odontología por la Universidad Nacional de La Plata (Argentina). Segunda especialidad profesional en Didáctica Universitaria. Magíster en Administración de Servicios de Salud, maestría en Educación y diplomado en Endodoncia Clínica y Odontología Estética y Funcional. Docente universitario en la Universidad Andina del Cusco (UAC) y la Universidad Peruana Los Andes (UPLA) de Huancayo, hasta la fecha. Correo electrónico: biodentmyc@yahoo.es y cquintanillar@mail. upla.edu.pe. https://orcid.org/0000-0002-2225-2888
} 


\section{The quaternity of learning styles and the Phisca-tawa code in the Inca educational system}

\section{Abstract}

The educational theory of learning styles seeks to develop meaningful learning in students in order to provide them with adequate professional skills, for which it is a relevant pedagogical vision in the current educational field. From another standpoint, current research is rediscovering the Inca worldview and allowing the theorizing of a good learning system called in Quechua allinta, based on a code of evaluative principles that allowed the training of the kamayoq, who were the specialists in various fields of knowledge. This study allows us to analyze the possible parallelism of current learning styles with the ancient educational worldview of the Incas, because despite referring to different educational contexts, they allowed the achievement of the technical abilities of the Inca kamayoq, which is similar to the skills of the current professional.

Keywords: learning styles, Inca worldview, Phisca-Tawa code, Inca educational system.

\section{A quaternidade de estilos de aprendizagem e o código Phisca-tawa no sistema educacional inca}

\section{Resumo}

A teoria educacional dos estilos de aprendizagem busca desenvolver uma aprendizagem significativa nos alunos, para alcançar habilidades profissionais adequadas, sendo uma visão pedagógica relevante no atual campo educacional. Por outro lado, a pesquisa atual está redescobrindo a visão de mundo inca e permitindo a teorização de um bom sistema de aprendizado chamado em quíchua allinta, baseado em um código de princípios avaliativos que permitia a formação de especialistas em diversas áreas do conhecimento, conhecido como kamayoq. Este estudo nos permite analisar o possível paralelismo dos estilos atuais de aprendizagem com a antiga visão educacional do mundo dos incas, porque, apesar de se referirem a diferentes contextos educacionais, permitiram o alcance das capacidades técnicas do kamayoq inca, semelhantes às habilidades do profissional atual.

Palavras-chave: estilos de aprendizagem, visão de mundo Inca, código Phisca-Tawa, sistema educacional inca. 


\section{INTRODUCCIÓN}

El estudio de los estilos de aprendizaje, relacionado con el enfoque pedagógico del constructivismo, busca la construcción de aprendizajes significativos, pero sus orígenes se pueden encontrar en el concepto de cuaternidad de los tipos psicológicos de Jung (1985) que luego se llevan al campo educativo por los Kolb (2005) con el nombre de estilos de aprendizaje, descritos en un proceso circular y enmarcados en cuatro fases, que se ordenan y desarrollan en forma progresiva para el logro último de las capacidades y habilidades de cada estudiante, siendo una herramienta innovadora para los docentes en el campo educativo actual.

De los incas se reconoce actualmente sus grandes logros en campos como la astronomía, la textilería, el manejo de semillas, de productos agrícolas como la papa o el maíz, las técnicas hidráulicas, la arquitectura y grandes construcciones que para nuestro tiempo son difíciles de igualar; pero no se ha tomado conciencia que debieron estar lógicamente fundamentados en una estructura educativa que se puede rescatar a través de documentos o crónicas registrados en tiempos de la colonia, muchas veces contradictorios por la interpretación subjetiva y por la dificultad en las traducciones orales, como sustenta Guerreira (2004), y mediante las abundantes investigaciones actuales sobre una cosmovisión sustentada en un sistema de cuatro etapas llamado código tawa, como lo describen Urton (1981) o Salazar (2014), que les permitió ordenar todos sus procesos productivos y debió influir profundamente en su concepción educativa.

Garcilaso (2009) habla ampliamente sobre los centros de enseñanza inca llamados yachay-wasi que define como casas de saber o casas de enseńanza, pero sin una información específica sobre el proceso educativo que regía en estas instituciones que debieron estar organizadas por contenidos y metodologías que buscaban la formación técnica y el aprendizaje académico, como opina Guerreira (2004).

El propósito de la presente investigación es observar y analizar la relación existente entre el proceso constructivo del aprendizaje en el sistema educativo actual y la ancestral técnica educativa inca, que conceptualizaba el mundo como un proceso de ordenamiento natural de cuatro elementos, en una estructura cíclica organizada por un quinto elemento, para alcanzar las capacidades técnicas del kamayoq o especialista inca. 


\section{Desarrollo}

\subsection{La cuaternidad del aprendizaje}

Jung (1985), figura clave en la etapa inicial del psicoanálisis junto a Freud, y gran investigador de antiguas culturas, corrientes filosóficas y conocimientos de ancestrales civilizaciones, redescubre el concepto de "cuaternidad», arquetipo universal o premisa lógica de todo juicio de totalidad que se basa en los postulados filosóficos de Aristóteles que llega a la conclusión de que la naturaleza tiene en total cuatro elementos o raíces: tierra, fuego, aire y agua; que se amplía con las teorías del médico Hipócrates que relacionan estos elementos con cuatro humores internos del cuerpo, los cuales determinan cuatro tipos de temperamentos en los seres humanos.

Jung (1985) moderniza los antiguos conceptos sobre los cuatro temperamentos hipocráticos convirtiéndolos en un sistema de tipologías psicológicas, como también sustenta posteriormente Martínez-Abascal (2001): «los distintos tipos constitucionales también determinaban aspectos psicológicos de las personas» (p. 412), cuatro tipos psicológicos que representan cuatro funciones básicas y principales de consciencia conocidos como tipos psicológicos de Jung (2002), cuatro formas de comprender e interpretar la realidad:

Por ello también hay cuatro aspectos psicológicos de la orientación psíquica más allá de lo cual no puede ya decirse nada más fundamentalmente. Debemos tener, como orientación, una función que compruebe que hay algo (sensibilidad), una segunda que verifique qué es esto (pensamiento), una tercera función que diga si esto se adecúa o no, si se quiere admitir o no (sentimiento) y una cuarta que indique de dónde viene y adónde va (intuición). (Jung, 2002, p. 474).

A través de la sensación el estudiante descubre o percibe el nuevo conocimiento, el pensamiento le indica de qué trata ese conocimiento, el sentimiento le permite otorgarle valor al conocimiento y la intuición le da el alcance de lo que puede hacer con ese nuevo conocimiento siendo una función final procedimental, por tal razón si no se atraviesa este proceso del conocimiento, no se logrará un desempeño adecuado y tampoco el éxito deseado. Los dos primeros tipos son más receptivos o pasivos y los dos últimos son más activos o de respuesta, de las cuatro existe el predominio de un tipo o función principal que es superior por predisposición natural conocida como carácter. Pero Jung (1985) refiere que se debe desarrollar todas las funciones o tipos psicológicos en forma integrada, porque ninguna de ellas por sí sola basta para alcanzar el conocimiento. 
Los tipos psicológicos son posteriormente reformulados por los Kolb (2005) en un modelo de aprendizaje teorizado como una rueda de cuatro etapas de "aprendizaje experiencial» denominados estilos de aprendizaje, que comprenden la experiencia concreta, la observación reflexiva, la conceptualización abstracta y la experimentación activa, siendo los dos primeros más receptivos y creativos y opuestos a los dos últimos que son más lógicos y ejecutivos. El proceso educativo basado en los estilos de aprendizaje es confirmado por investigaciones sobre neurociencia y función cerebral, como las del neurobiólogo Zull (2002) que afirma: "la experiencia concreta viene a través de la corteza sensorial, la observación reflexiva involucra la corteza integradora posterior, creando nuevos conceptos abstractos que ocurren en la corteza integrativa frontal y las pruebas activas involucran al cerebro motor» (pp. 18-19). De este modo, el ciclo del aprendizaje surge naturalmente en la estructura interna del cerebro (figura 1).

Figura 1. El ciclo del aprendizaje experiencial y las regiones de la corteza cerebral

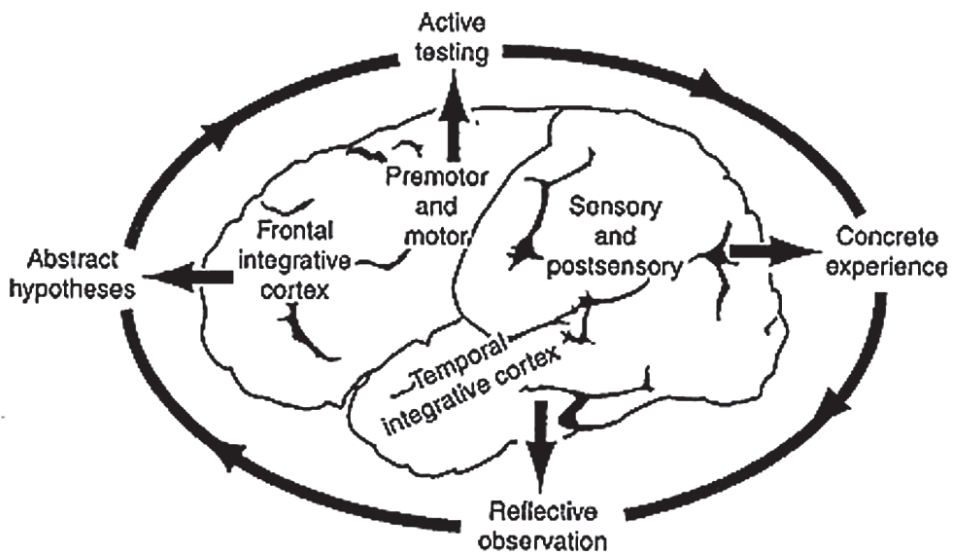

Fuente: The Art of changing the brain (Zull, 2002, p. 18).

Renés y Martínez (2015) indican que la visión de estilos de aprendizaje iniciada por los Kolb (2005) se basa en enfoques cognitivos del aprendizaje, y representa un modelo educativo experimental de cuatro etapas luego transformado por Alonso, Gallego y Honey (2012) a un instrumento en idioma castellano, más detallado que el de los Kolb (2005), por estar basada en las acciones que desarrolla el estudiante. Alonso et al. (2012) indican que los estilos de aprendizaje forman parte de enfoques pedagógicos contemporáneos 
que buscan el aprender a aprender, y definen cada estilo de la siguiente manera: estilo activo (experiencia concreta de los Kolb), estilo reflexivo (observación reflexiva de los Kolb), estilo teórico (conceptualización abstracta de los Kolb) y estilo pragmático (experimentación activa de los Kolb), por tanto cada estudiante debe desarrollar secuencialmente cada uno de los cuatro estilos de aprendizaje para culminar en forma exitosa todo el proceso de enseñanza y para que cada estudiante pueda construir un aprendizaje significativo para su vida profesional.

\subsection{El aprendizaje inca de cuatro valores}

Los incas interpretaron su entorno natural y cultural en una cosmovisión expresada mediante su lengua materna quechua o mejor llamado qheswa simi ${ }^{1}$, relacionando el orden de los cielos y de las estrellas con el entorno geográfico de la tierra llamada Pachamama. Por eso las cuatro estrellas de la constelación de Orión, llamada Hatun Chakana en quechua, señalan a cada uno de los cuatro suyos, como lo ha probado Salazar (2014), ordenando el entorno geográfico del Tawantinsuyo que fue fundado por cuatro hermanos llamados Ayar; una cosmovisión de cuatripartición simbólica y funcional que Jung (1985) interpretaba como un arquetipo de cuaternidad, y que era conocida por los incas con el concepto quechua de tawa.

El investigador Urton (1981) descubrió a través de las tradiciones orales el «universo quechua de las constelaciones oscuras» de los incas, que distinguían manchas oscuras contra el fondo claro de la Vía Láctea que era el gran río cósmico (figura 2), describiendo siluetas de animales que se elevan a lo largo del río celeste destacando cuatro de ellas que rodean a la Cruz del Sur y que emergen cíclicamente acompasando el ciclo agrícola, como fueron descritas por Cáceres (2007) y Urton (1981): a la derecha la rana o sapo celestial llamada hanp'atu o atarway, llamada también pachawawa en quechua por ser hijo espiritual de la tierra, que se observa en los cielos nocturnos en el mes de agosto anticipando el tiempo de siembra; más a la derecha, la silueta de yacumama, amaru o mach'aqway que es la gran serpiente de agua que se observa al inicio de la temporada primaveral de lluvias en la sierra; a la izquierda de la Cruz del Sur se encuentra la constelación con forma de ave llamada yutu o lluthu en la nebulosa oscura llamada saco de carbón, que se observa en el tiempo de lluvias y fructificación de diciembre, reflejándose en tierra con la figura de un gran ave descubierta por Salazar (2014) entre los andenes del complejo

1 Como lo define la Academia Mayor de la Lengua Quechua (2013, p. 158) 
arqueológico de P'isaq; finalmente, hacia el noroeste se encuentra la gigantesca figura de una llama cuyos ojos brillantes lo forman las estrellas Alfa y Beta Centauri, conocida como yacana o katachillay que se observa en el tiempo seco de otońo cuando culminan las cosechas de abril y mayo, reflejada en la figura de una llama descubierta por los hermanos Elorrieta (2008) en los andenes de la ciudadela inca de Ollantaytambo. Las cuatro constelaciones se pueden relacionar con los cuatro elementos descritos en la mayoría de las cosmogonías de civilizaciones antiguas.

Figura 2. Constelaciones oscuras

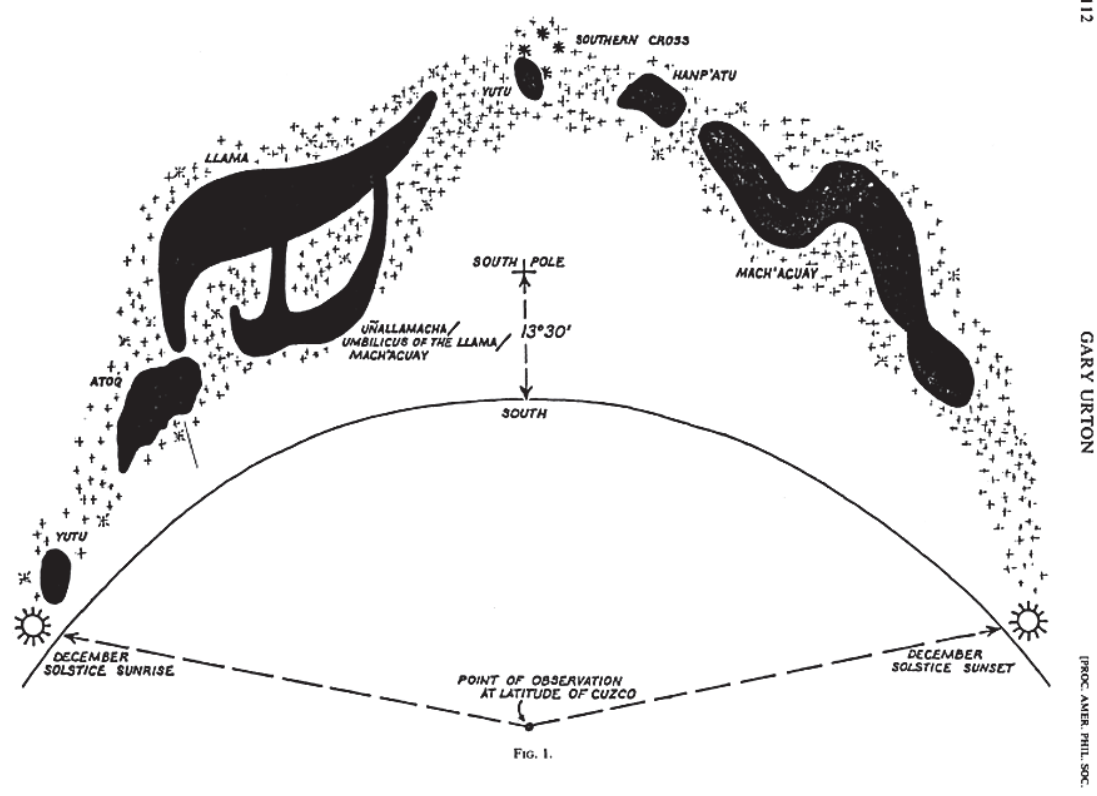

Fuente: Animals and Astronomy in the Quechua Universe (Urton, 1981, p. 112).

Estas cuatro constelaciones están rodeando a la Cruz del Sur, que representa la máxima sacralidad inca y simboliza el ordenamiento natural basado en el principio tawa o de los cuatro principios valorativos, culturales y educativos que conocían los incas, siendo un pueblo «que marcaba el paso de sus vidas con la celebración de rituales adecuados a cada circunstancia» (Guerreira, 2004, p. 411). Así lo muestran los Arsuwinakas o mandamientos aimaras rescatados mediante el código ético kinthu, descrito en una publicación del Ministerio de Relaciones Exteriores de Bolivia (2009). Los Arsuwinakas representan cuatro principios: akhamaña, que significa vivir; yatiña, que es el saber; 
amuyaña, que es sentir, y luraña, que significa construir o hacer. Los incas, por su parte, tenían el código tawa nombrado por Laurencich (2003), que también describía cuatro valores: kawsay que es vivir o existir, yachay que es aprender, munay que es querer y llank'ay que es laborar, valores que ordenaban todas sus actividades siendo los dos primeros de tipo receptivo, pasivo o femenino relacionadas con celebraciones a la germinación con las diosas Pachamama o madre tierra y Yacumama o madre agua; y los dos últimos de carácter activo, productivo o masculino con celebraciones a los dioses Kon que era el dios del viento y Pachakamaq que era el dios del fuego terrestre.

Podemos interpretar de lo anterior que la actividad educativa del aprendizaje inca, desarrollado en los Yachay wasi, Yachana wasi o Hatun Yachay Wasi, equivalente a la universidad actual $^{2}$, se desarrollaba mediante un ordenamiento similar, impartiéndose la formación técnica y la preparación especializada a los príncipes incas y a los hijos de los hombres principales de los pueblos conquistados con un lengua secreto desconocido hoy en día y un sistema de quipus nemotécnicos que representaban conceptos abstractos que asombraban a los conquistadores; conocimientos superiores enseñados a través de maestros llamados Yachachiq o Yachayniyoq, en un nivel de educación superior, como lo sustenta Guerreira (2004), que también comenta: «no puede negársele el perfeccionamiento de las técnicas por la preparación especializada en cada una de ellas, que confiaron a los más hábiles» (p. 412).

Se trataba de conocimientos muy específicos y prácticos que «no surgen de la simple intuición, ni de la sensibilidad o capacidad de observación de un individuo, y responden a un sistema de reglas o modos y que proporciona los medios para darle una utilidad práctica» (Guerreira, 2004, p. 414), y que estaban sustentados en el concepto allin o allinta que significa bueno, espléndido o magnífico, según el diccionario de la Academia Mayor de la Lengua Quechua (2013) ${ }^{3}$, que representaba el compromiso de hacer bien las cosas.

\subsection{El estilo activo del allin kawsay}

Kawsay significa vivir y kawsay pacha o kaypacha es la tierra en que vivimos, y la Pachamama, Sachamama o Hachamama, la tierra fértil en que nacemos, existimos y venimos a aprender. Allpacamasca en los mitos andinos es llamada por Garcilaso (2009) tierra animada, y Hallp'a en quechua significa tierra cultivable, tierra con energía creadora latente que llevada al nivel humano representa la capacidad creativa, la inventiva y la capacidad de desarrollar su erudición.

\footnotetext{
Definición de la Academia Mayor de la Lengua Quechua (2013, p. 158).

Diccionario que se utiliza en este trabajo para las traducciones del quechua al castellano.
} 
Kawsay es: «vida en realización permanente, dinámica y cambiante... interacción de la totalidad de existencia en movimiento, la vida entendida desde lo integral, es la esencia de todo ser vital» (Macas, 2010, p. 23).

El tiempo de siembra de la tierra es el Tarpuy mit'a (figura 3), que era el tiempo de arar la tierra y sembrar la semilla: "este mes entran a trabajar, aran y rompen tierras simples para sembrar maíz» (Poma, 1980a, p. 175).

Figura 3. Zara Tarpuy Mit’a (tiempo de sembrar el maíz)

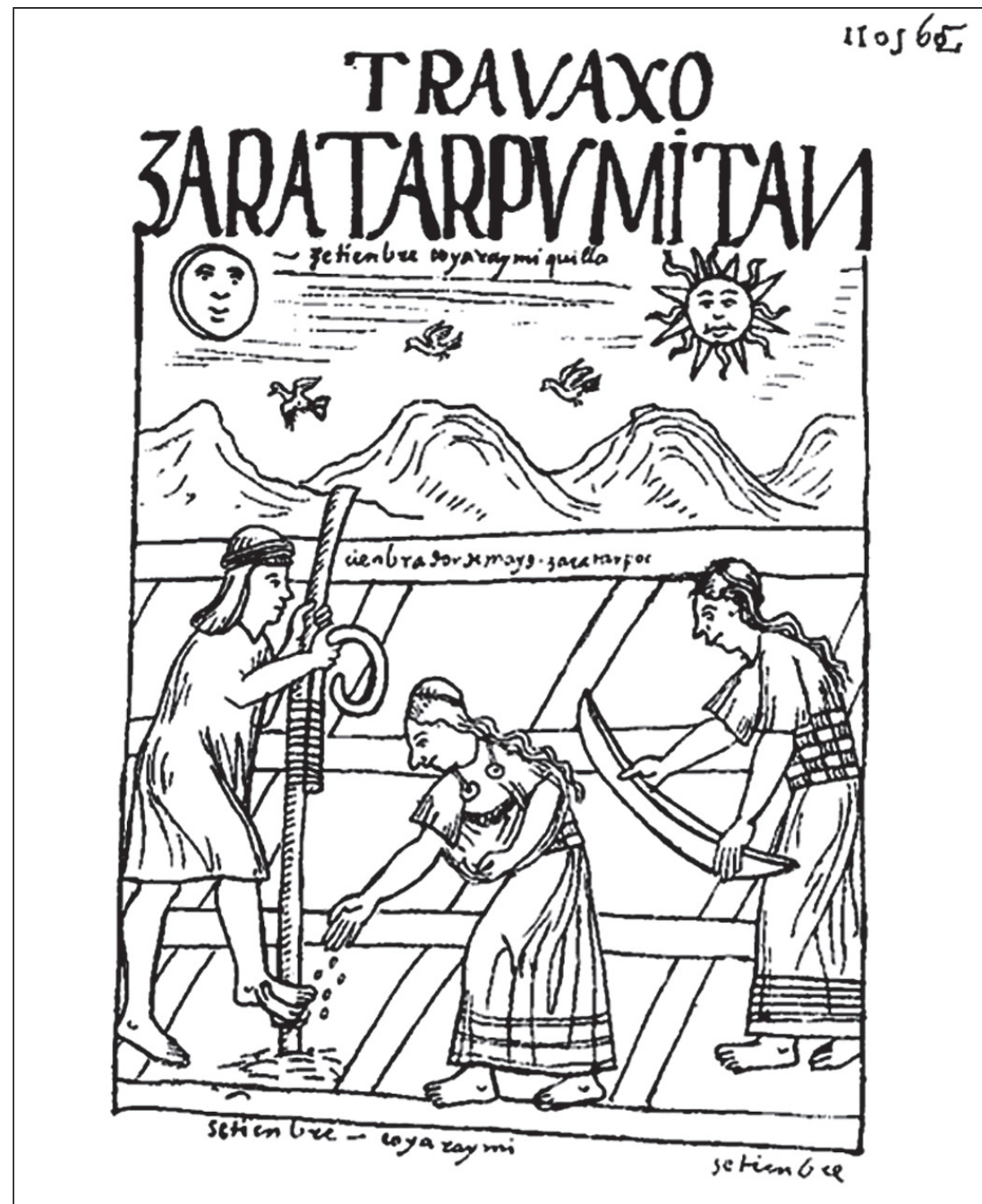

Fuente: Nueva corónica y Buen gobierno. Tomo II. (Poma, 1980b, p. 468). 
Es la tierra donde se inicia el ciclo agrícola cuando se sale del invierno al tiempo primaveral. Este periodo comienza con la purificación de la tierra en la ceremonia del Situwa o Sitwa Raymi, que simboliza la purificación de la madre tierra Pachamama y la pachawawa seca y enferma por el frío invernal para recuperar su Kamaq o Kawsa, ceremonia celebrada en julio cuando se pasaba de la sequía al tiempo de lluvia, que en la actualidad se rememora con la fiesta del Apóstol Santiago, llamado también Tayta Shanti o Apu Wamani: «en el Cuzco comienza temprano el mes de Santiago, y si yerra... se daña el maíz» (Poma, 1980b, p. 466). Luego en setiembre se celebraba el Qoya Raymi: «la gran fiesta de la luna, es coya y señora del sol... y así fue fiesta y pascua de la luna» (Poma, 1980a, p. 179), celebración en honor a la esposa del inca, a la tierra y a lo femenino como elementos de fecundidad para propiciar el inicio de la siembra agrícola.

En el inicio del aprendizaje el docente también actúa como un tarpuq o sembrador que comienza a sembrar las semillas del conocimiento en el estudiante mediante preguntas, diálogos, ideas, ejemplos y conceptos. El estudiante activo se caracteriza por: «implicarse en experiencias, entregarse a la realización de actividades novedosas... le gusta desempeñar un papel activo tanto en la experiencia como en las relaciones personales» (Renés y Martínez, 2015, p. 167), como la tierra fértil (allin kawsay) apta para implicarse en la experiencia educativa.

\subsection{El estilo reflexivo del allin yachay}

Yachay es el conocimiento o sabiduría que entrega el yachachiq que es el maestro o profesor, el yachayniqoq que se traduce como docto, erudito o catedrático que instruye, educa o enseña lo que no sabe o ignora el estudiante.

Macas (2010) indica que yachay es: "generar pensamiento, un aprendizaje permanente... una práctica de generación en generación, dentro de nuestras comunidades» (p. 27). Por su parte Lajo (2006) lo relaciona con la cabeza «que traduce el principio del saber o la sabiduría, zona del Hanan Pacha; el que lo cultiva es un Yachayniyoq, un ser pensante, gran teórico descifrador de razones y palabras, pero nada más» (p. 139). El Yachay estaba representado con el amaru, la serpiente andina "que representa sabiduría y que encarna la trinidad vida-muerte-eternidad, cuyo simbolismo se transforma con el correr de los tiempos y los contextos culturales... agente transformador e impulsor de cambios estructurales para los pueblos andinos» (García, 2017, p. 24). La serpiente también es símbolo de las lluvias y la fertilidad según Tacca (2012), y para los incas era tótem y símbolo de sapiencia, por tal razón 
los yachay wasi eran edificaciones adornadas con abundantes relieves de serpientes, símbolo del aprendizaje y del pensamiento racional, como lo atestigua la llamada actualmente "casa de las sierpes», el principal Yachay wasi del Cusco en el Amaruqhata o ladera de la serpiente del barrio inca de Pumacurcu, que significa columna del puma, a orillas del hoy canalizado río Tullumayu o Tulumanya, que significa arco iris ${ }^{4}$.

Las pacarinas, qochas o pukyus son las aguas subterráneas que originan la cultura porque, según la cosmovisión inca y pre-inca, comunican el ukhupacha o mundo interior oscuro de la tierra con el mundo exterior luminoso del kaypacha. El ukhupacha por tanto es «de donde sale toda la energía, lo que fluye del interior del tiempo y del espacio» (Lajo, 2006, p. 135). Según las leyendas orales, por estos lugares salen los hombres que han desarrollado el pensamiento reflexivo y la razón para desarrollar la cultura de los pueblos, como Manco Qapac y Mama Ocllo salen por la gran pacarina del Titicaca llenos de sabiduría para fundar un imperio, o como las pacarinas de Choclococha o Wariwillka que dan origen a las culturas Chanka y Wanka respectivamente; por lo demás, Paqariq significa despertar, que se puede traducir como el salir de la oscuridad de la ignorancia al amanecer del conocimiento con el aprendizaje de los yachay wasi.

El tiempo primaveral del Qarpay mit'a (figura 4) es descrito por Poma (1980b) como "mes de regar las chacras con agua de pozos o de represas» (p. 471), el trabajo agrícola de riego usando el agua de lagos, manantes o reservorios llamadas qochas o pacarinas que con su humedad proporcionen el agua para la germinación de la planta. En noviembre se celebraba el Ayamarcay: «es la fiesta de los difuntos, en este mes sacan los difuntos de sus bóvedas que llaman pucullo, y le dan de comer y beber, y le visten de sus vestidos ricos» (Poma, 1980a, p. 179), tiempo de momias y de muertos como si fuera un tiempo de morir a los viejos conocimientos para vestirse con el nuevo conocimiento impartido.

Es el momento en que el docente es el yachachiq o yachayniyoq, el erudito que actúa como el reservorio o la fuente de nuevos conocimientos o saberes, y hace brotar la reflexión y la comprensión en los estudiantes que, luego de ser semilla, se transforman en el neófito o la nueva planta. El estudiante reflexivo destaca por «la prudencia y la reflexión profunda a la hora de tomar decisiones y de actuar» (Renés y Martínez, 2015, p. 168), es el que piensa bien (allin yachay), analizando y reflexionando sobre la experiencia educativa desde

4 Traducción del quechua wanka o huanca. 
diferentes perspectivas y después de un minucioso análisis llega a la luz de la comprensión racional.

Figura 4. Zara Qarpay Mit’a (tiempo de regar el maíz)

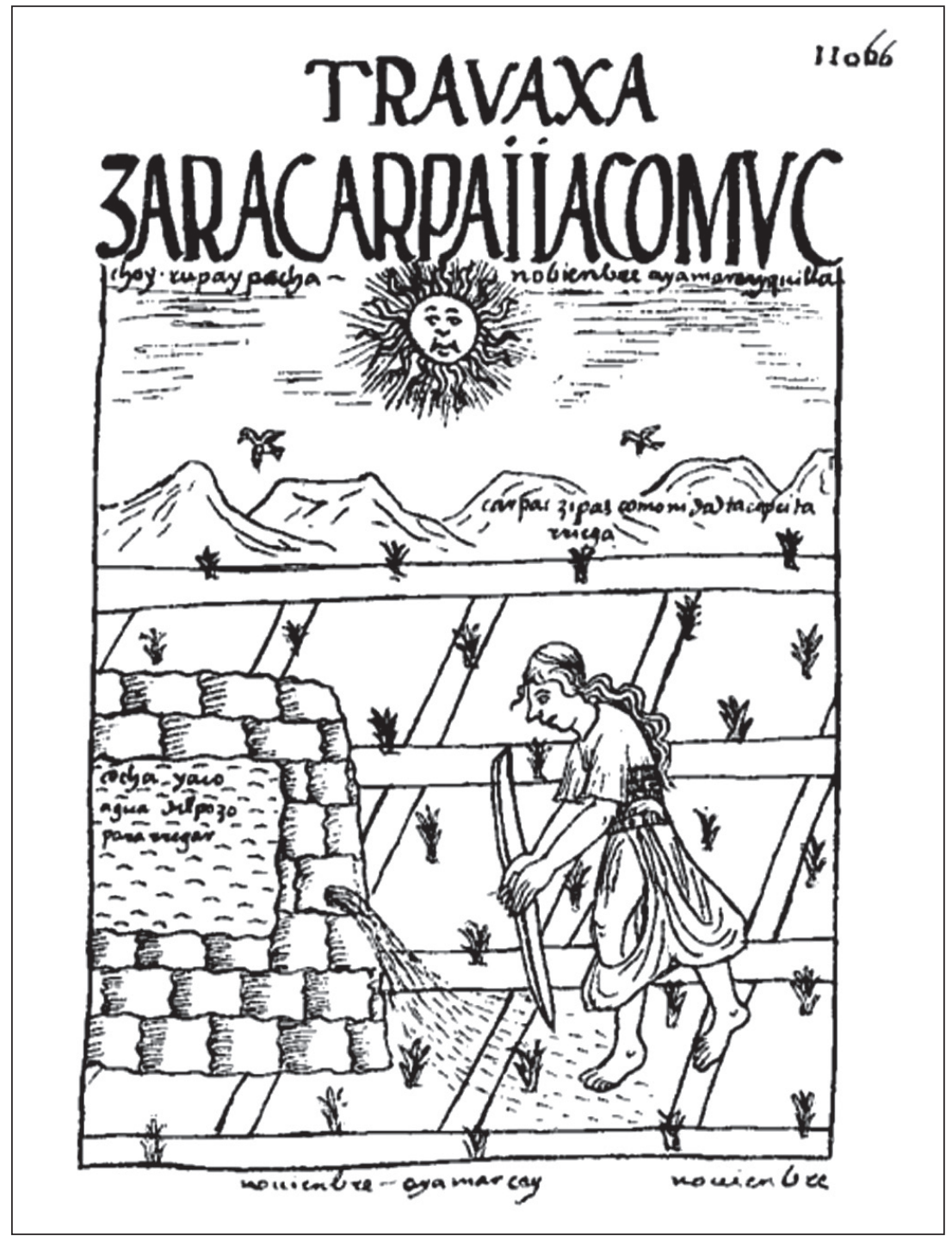

Fuente: Nueva corónica y Buen gobierno. Tomo II. (Poma, 1980b, p. 472) 


\subsection{El estilo teórico del allin munay}

Munay es voluntad, ánimo o deseo, y munayniyoq es la persona voluntariosa o con poder de decisión. El munay, según Macas (2010) «tiene que ver con la voluntad, la afectividad, con la necesidad de apasionarse, querer, la capacidad de entregarse, el consentimiento, el compromiso y consecuencia con algo, los sueńos y los propósitos» (p. 28); representa por tanto procesos de compromiso y la búsqueda de propósitos específicos u objetivos determinados encausados por la voluntad.

El munayniyoq, según Lajo (2006), "hará magia con su capacidad y potencia para sentir y proyectar la fuerza del munay, y hasta podrá volar en las alas de la pasión organizada que procrea nuestra cultura» (p. 136), como el viento del dios costero Kon Wiraqocha, con forma de ave, que gobierna los vientos que cuando pasaban a las montańas propiciaban las abundantes lluvias en la sierra para la producción y procreación agrícola y ganadera del verano.

Era el tiempo de verano con lluvias abundantes, propicias para la producción agrícola, que Poma (1980b) describe como tiempo de aporque en el Hallmay mit'a de enero: "el comienzo del gran aguacero, y llueve mucho... y tienen que trabajar de limpiar chacras... estando ojeando el maíz y papas de los perdices, y de los venados y de la zorrilla, en todo el reino» (p. 448), el trabajo aporcando o arrimando tierra en la base de las plantas cultivadas con montículos o camellones para lograr el drenaje del exceso de lluvia nocivo para los cultivos, eliminando malezas y yerbas nocivas, y ahuyentando a las alimañas (figura 5). Está la época del Pacha phukuy en que «ya tienen qué comer... y en este mes cesan de hambre en el reino; así los ganados están ya gordos, hay pasto de sobra» (Poma, 1980a, p. 171), porque el viento que significa pokoy o el aliento que se dice samay traen las lluvias que permiten el desarrollo a plenitud de los cultivos, el crecimiento de los pastos y del ganado que empezaba a dar cría y engordar para dar alimento a los pobladores en un tiempo florido y multicolor de exuberancia y belleza.

Es el momento en que el docente se desempeña como un munayniyoq, que compromete y anima al estudiante a llevar el conocimiento ya reflexionado a una etapa de mayor abstracción y de mayor síntesis teórica que le permita comprender el propósito de su aprendizaje; y es también el consejero que le ayuda a interpretar el conocimiento y a desechar la información innecesaria, las dudas o inquietudes como se desecha la yerba o las alimańas nocivas. El estudiante teórico "tiene la tendencia a analizar y sintetizar desde la racionalidad y desde la objetividad... sigue procesos sistemáticos cuando aborda los problemas y valora lo metódico y lo estructurado» (Renés y Martínez, 
2015, p. 169); es por tanto el estudiante voluntarioso, decidido y estructurado (allin munay) que ordena en forma coherente, sistemática y lógica el conocimiento aprendido.

Figura 5. Zara Hallmay Mit’a (tiempo de aporque de maíz y papa)

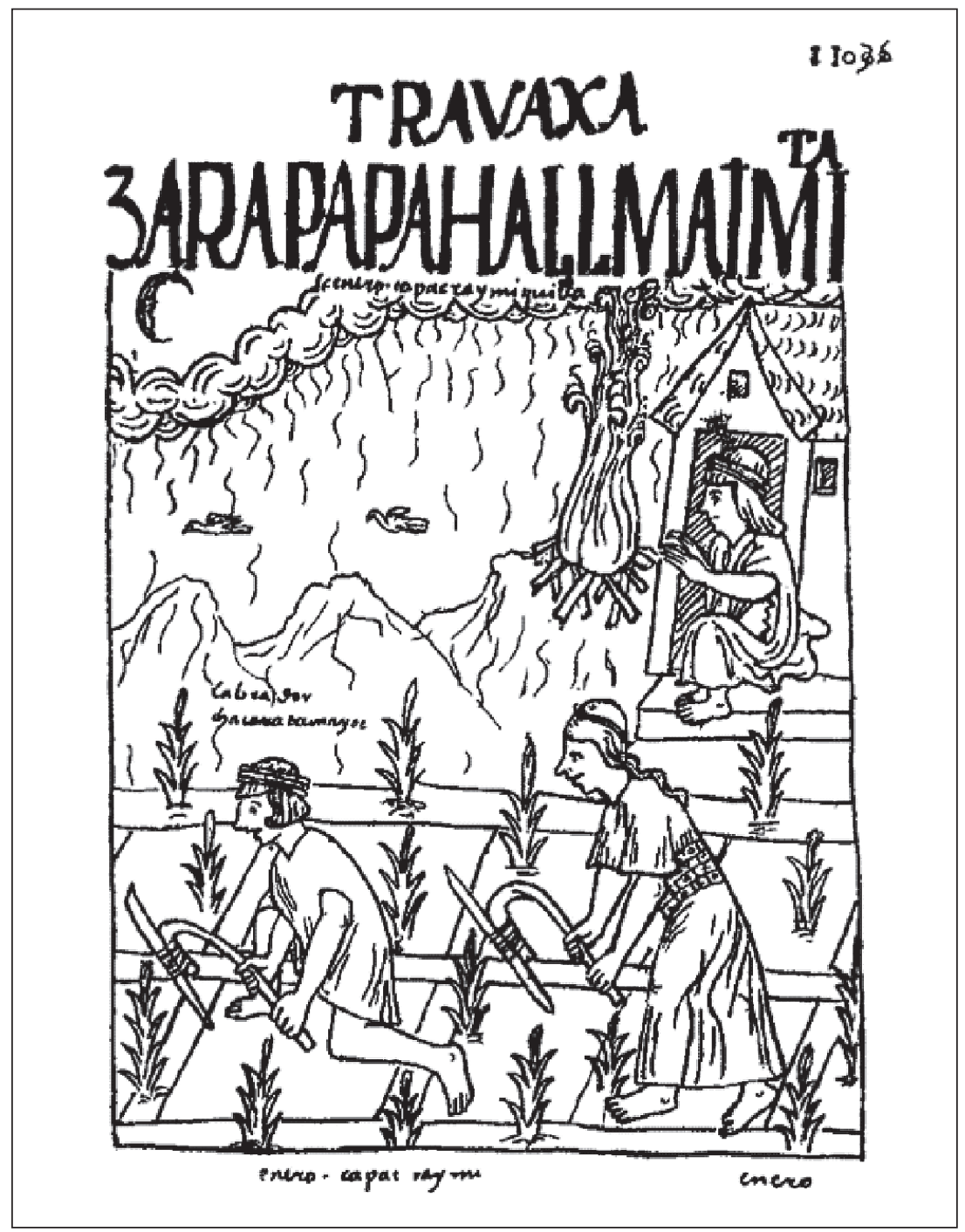

Fuente: Nueva corónica y Buen gobierno. Tomo II. (Poma, 1980b, p. 449). 


\subsection{El estilo pragmático del allin llank'ay}

Llank'ay o Ruway es trabajo, labor, tarea u ocupación que desarrolla el trabajador, llamado llank'aq en quechua. Para el investigador Lajo (2006), "Llankay o Ruay... es el hacer o laborar o más llanamente el principio del trabajo, que es la esfera del Kay Pacha, que en el organismo humano lo ocupa la zona del estómago (ombligo)» (p. 136), concepto confirmado científicamente al ser el sistema digestivo el encargado de la absorción de nutrientes que luego el hígado utiliza para conseguir la energía calórica necesaria para el trabajo. Para Macas (2010), «Ruray, se refiere al hacer, experimentar, crear, promover, intervenir, potenciar; estos procesos son colectivos y comunitarios...» (p. 27). El fuego es, por tanto, un elemento calórico que impulsa procesos de creación, acción y producción a través de dioses del fuego como el Huallallo Carhuincho de los huancas en la región central o Ychsma-Pachacamac en la costa, que según Eeckhout (2004) expulsa al dios Kon como símbolo de la transición del verano al otońo cálido y seco que promoverá la maduración final de los frutos y el logro de la cosecha.

El tiempo otoñal era llamado por los incas Allay mit’a, y era el tiempo de participar en las grandes cosechas «...y guardar la semilla de las papas y ocas, ollucos, masua, quinua y es tiempo de segar trigo en todo el reino (figura 6). Y de las demás comidas y frutas se ponga en piruas (despensas) cullunas» (Poma, 1980b, p. 460); y era tiempo de las grandes fiestas como el el Inca Raymi Quilla donde el Inca convidaba por igual a los principales y a los pobres, y «cantaba el cantar de los carneros - puca llama - y cantar de los ríos... este mes está la comida madura y ansí comen y beben y se hartan la gente del reino a costa del Inga» (Poma, 1980a, p. 171), o el Aymoray Quilla que se celebraba luego: «de recoger la comida y llevarlo a casa o al depósito, para guardarse en las cullunas chauays pirua, que son barriles hacen muy mucha fiesta y borrachera, cantan...» (Poma, 1980a, p. 171), un periodo de bienestar y regocijo para todos los habitantes del Tawantinsuyo.

El docente cumple en esta etapa educativa la función final de llank'aq porque promueve la maduración final del aprendizaje del estudiante potenciando sus aptitudes, habilidades y destrezas para que pueda aplicar los conocimientos aprendidos en forma práctica, e interviene evaluando comunitariamente el desempeño de los estudiantes para así poder cosechar los logros académicos del proceso de enseñanza y aprendizaje. Al estudiante pragmático le interesa «la aplicación de las ideas, de las teorías y de las técnicas para comprobar su funcionamiento... poner al instante en práctica las ideas, encontrar beneficios a los que realiza y ver con naturalidad la practicidad de todas las actuaciones» 
(Renés y Martínez, 2015, p. 170). Es por tanto el estudiante práctico que desempeña bien su labor técnica (allin llank'ay) porque demuestra capacidad ejecutiva, trato agradable, disciplina, autocrítica y capacidad de análisis para solucionar las eventualidades que se puedan presentar durante su desempeńo.

Figura 6. Allay Mit’a (tiempo de maduración y cosecha)

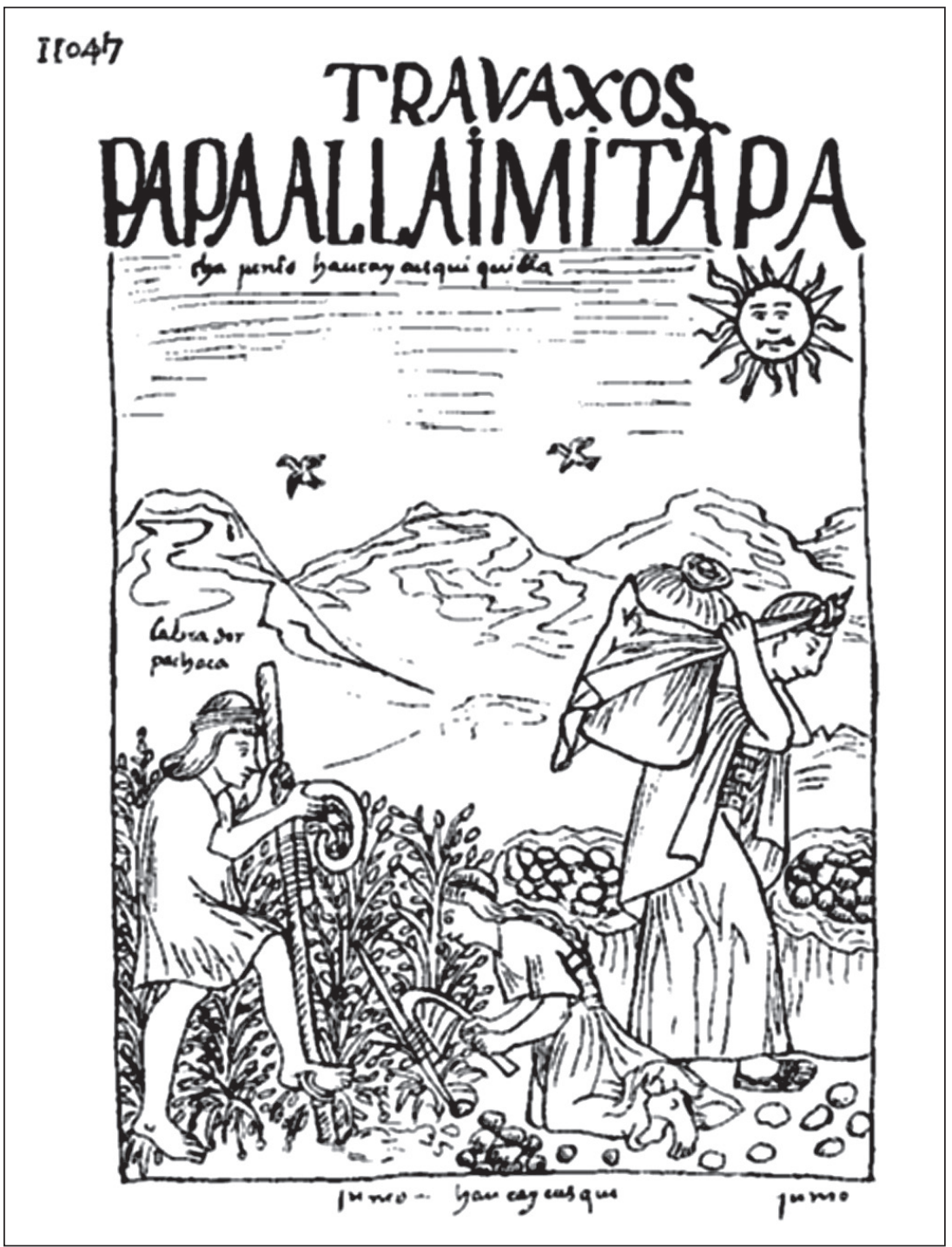

Fuente: Nueva corónica y Buen gobierno. Tomo II. (Poma, 1980b, p. 461). 


\subsection{La culminación del aprendizaje inca: el Kamayoq o especialista}

En la ceremonia del Inca Raymi Quilla (figura 7) el Inca entonaba un harawi o yaraví inca homenajeando a una puka llama o llama roja, probable referencia de la constelación oscura con tonos rojizos de la yacana que a comienzos del mes de mayo acompaña a la Cruz del Sur que también era conocida como chacana o yakana: «al parecer es una palabra deformada y derivada de Llama Kamaq o el animador espiritual... es decir, el jefe, el que dirige. En suma una illa celestial oscura» (Salazar, 2014, p. 248). Era por tanto «uno de los indicadores más notables de la manipulación de tales manifestaciones como emblema de poder» (Gudemos, 2005, p. 32). Kamay es crear, inventar, modelar o plasmar, y Kamaq es el creador o inventor, siendo por tanto un símbolo espiritual creador y ordenador de la naturaleza.

Ambas constelaciones se observan al final del ciclo agrícola, por tanto la relación de la Cruz del Sur y los periodos de riego «han determinado que se le llame Chakana agrícola (...) haya sido en la antigüedad la señal para el inicio de la cosecha y con ella las celebraciones a esta constelación que luego sería reemplazada por el signo cristiano» (Salazar, 2014, p. 208). Por eso en la actualidad se celebra a la Cruz de mayo, Tayta mayo o Cruz Velacuy (velación de la cruz), fiestas que cambian de denominación de acuerdo a la región, pero que aparentemente celebran la culminación de un ciclo total de creación.

La investigadora Gudemos (2011) descubrió el código de medición phisca-tawa en la música incaica, pero «lo que reviste mayor importancia es la posibilidad de utilizar este sistema en todos los órdenes que requieran mediciones de precisión, puesto que la matriz pichqa-tawa es adaptable a toda longitud que oportunamente se considere para efectuar demarcaciones» (p. 242). Esto permite determinar que un orden de cuatro elementos es complementario con un quinto elemento, como las cuatro constelaciones incas $($ tawa) que complementan o rodean a la Cruz del Sur que representaría el quinto elemento (phisca), como cuenta la leyenda de Huarochirí descrita por De Ávila (2009) sobre el dios Pariaqaqa Wiraqocha, que es el dios solar que nace de cinco huevos para desplazar al dios ctónico Huallallo como símbolo del quinto elemento que en un proceso creador ordena los cuatro elementos inicialmente caóticos de la naturaleza, como lo describe Mayta (2012): «cuando no existía aún ni la nada y la Pachamama (Madre Tierra) aún humeaba; existió primero Wira (Roca), Kocha (Agua), Kon (Fuego) y Tikse (Luz). De la unión de estos cinco espíritus nació Apu Kon Tikse Wiraqocha Pachayachachiq» (p. 24), y también Laurencich (2003), que indica: «el canto Pichca punchau (cinco días) nos deja entrever trazos de cosmogonía quinaria 
(el maíz brota al quinto día, el Sol alumbra al quinto día... el dios Pariacaca manda las cinco regiones del cielo)» (p. 5).

Figura 7. Fiesta de los Ingas (Inga canta con su Puca llama).

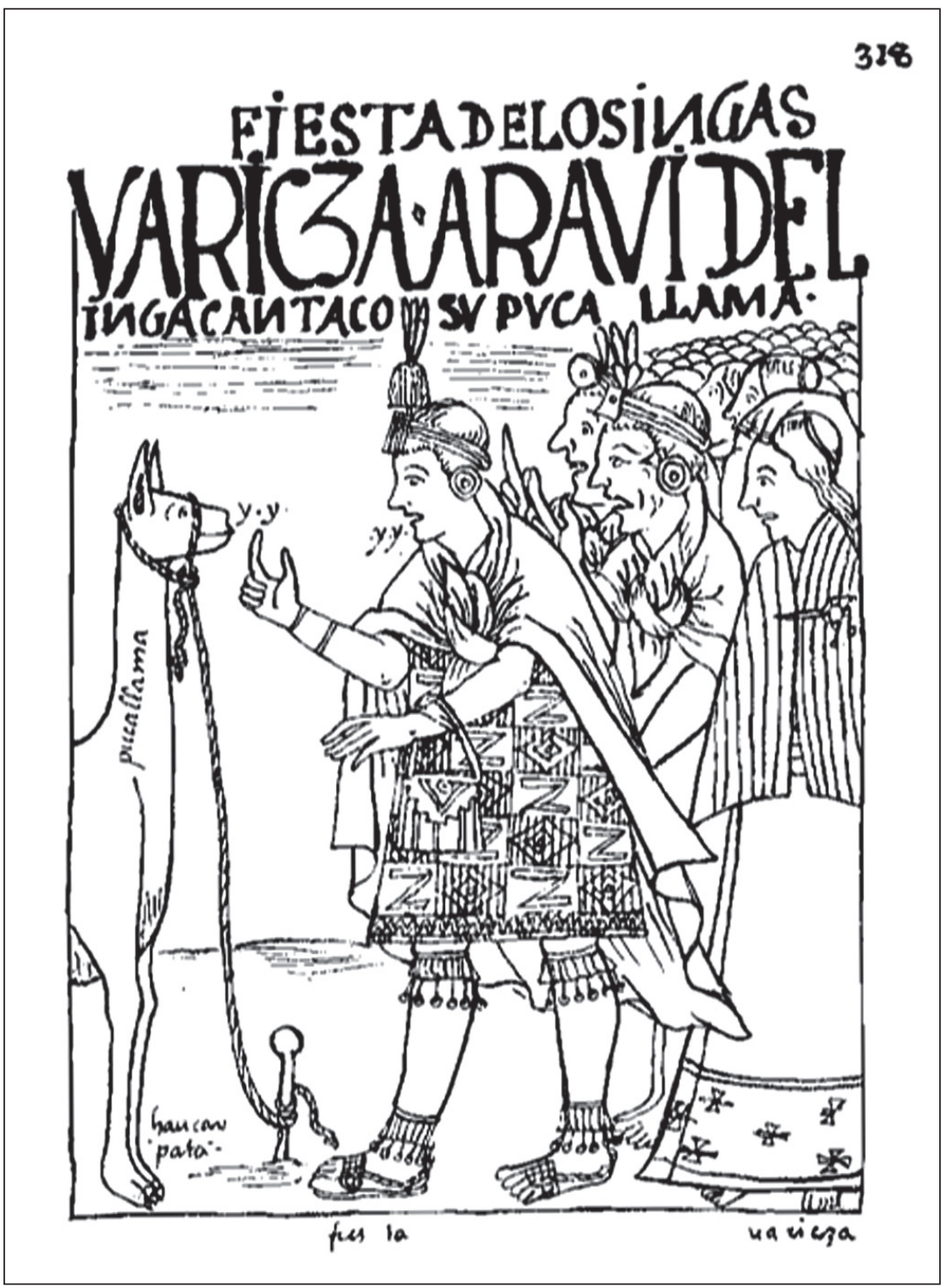

Fuente: Nueva corónica y Buen gobierno. Tomo I. (Poma, 1980a, p. 227). 
El proceso educativo constructivista también es un proceso creador gradual y cíclico como lo entiende Díaz (2010): «[Inicialmente] la información aprendida es concreta y vinculada al contexto específico... [Posteriormente] se vuelve aplicable a otros contextos...llega a ser más abstracto, es decir, menos dependiente del contexto donde originalmente fue adquirido... [Finalmente] existe mayor énfasis sobre la ejecución...» (pp. 45-47); es un proceso del aprendizaje significativo que une el principio del kawsay con el final del llank'ay que Góngora (2015), denomina "Allin Kawsay Ruhuay, hacer bien las cosas, era y es la conducta cotidiana del poblador del mundo andino" (p. 184). Al completar su aprendizaje, el inca encarnaba el quinto principio kamaq que es la capacidad creadora de modificar la realidad, volviéndose un kamayoq que representa al perito o especialista con potestad o dominio sobre alguna labor, lo que Yates (2015) relaciona con la forma dinámica del aprendizaje del «aprender a hacer» del profesional actual como lo atestigua un largo listado que elabora, del cual extraemos algunos ejemplos: Quipu kamayoq: contador, matemático o astrólogo; Hampi kamayoq: médico o cirujano; Nina kamayoq: guía espiritual o sabio; Hachakachi kamayoq: ganadero; Qolqa kamayoq: administrador de qolqas o depósitos imperiales; Chakra kamayoq: labrador, agricultor; Q'umpi kamayoq: tejedor; Qolqi kamayoq: orfebre o joyero; Rumi ch'iquq kamayoq: constructor o arquitecto; Hochayca kamayoq: juez; Sañu kamayoq: alfarero, etc.

\section{CONCLUSIONES Y RECOMENDACIONES}

Los estilos de aprendizaje tienen dos propósitos, según indican los Kolb (2005)- - . Son una herramienta para el logro del aprendizaje significativo en los estudiantes que deben aprender a experimentar el proceso del aprendizaje activamente, aprender a reflexionar y razonar sobre lo aprendido, aprender a teorizar y comprender lo que se ha aprendido, y aprender a desempeñarse en forma práctica y óptima, de modo que cada estudiante pueda alcanzar las capacidades y competencias académicas. También son una herramienta para enseñar a los estudiantes el método de investigación: aprender a observar activamente la realidad para descubrir problemas, aprender a reflexionar para plantear preguntas y objetivos, aprender a teorizar las hipótesis y aprender a experimentar para llegar a conclusiones y resultados.

Respecto a la educación inca, Góngora (2015) comenta que el proceso de enseńanza-aprendizaje inca «era eminentemente práctico, se educaba no para conocer, sino para la práctica cotidiana, el que no conocía no podía entender su realidad, ni trabajar... la educación nunca dejó de estar vinculada al trabajo 
y para la vida real» (pp. 182-183); y como a todos los Hatun Runas se les enseñaba la labor más importante que era la agrícola, pudo significar también un ordenamiento educativo natural aplicado a todos los habitantes del reino para luego ser complementado en los Hatun Yachay Wasi donde solo los privilegiados o los más destacados se convertirían en los Kamayoq o especialistas que aprendían a generar procesos o productos para desempeńarse espléndidamente en una determinada labor, arte o actividad. Por tanto, la capacidad profesional de los actuales graduados podría asemejarse a la especialidad técnica del kamayoq, que para los incas reflejaba en la tierra la capacidad inventora y creadora que en los cielos era la divinidad del Kamaq o principio creador de todo lo existente, conocido como Wiraqocha Pachayachachiq o Pachakamaq, máxima deidad inca que la historiadora Rostworowski (1992) redescubre en un mágico sincretismo religioso como el Cristo de Pachakamillaq.

Por tanto, los estilos de aprendizaje que guardan relación con principios valorativos, culturales y educativos deben ser potenciados para conciliar la sabiduría inca con los conocimientos científicos actuales, en un sincretismo educativo, cultural y social moderno, haciendo de este modo accesible dichos conocimientos a nivel global porque permitirán sin duda contribuir a un mayor desarrollo y bienestar de nuestra sociedad.

\section{REFERENCIAS BIBLIOGRÁFICAS}

Academia Mayor de la Lengua Quechua. (2013). Simi Taqe: Diccionario Qheswa - Español-Quechua (4ta. ed.). Perú: REGESA S.R.L.

Alonso, C., Gallegos, D., y Honey, P. (2012). Losestilos deaprendizaje. Procedimientos de diagnósticos y mejora (8va. ed.). Bilbao: Editorial Mensajero.

Cáceres, E. (2007, marzo). Visión y función del Hamp'atu [Sapo] en la cultura indígena andina: una lectura de simbologías y significados. Volveré. Recuperado de http://www.iecta.cl/revistas/volvere_24/articulo_3_volvere_24.htm

De Ávila, F. (2009). Dioses y hombres de Huarochirí. Narración quechua recogida por Francisco de Ávila [i1598?]. (Traducido por J. M. Arguedas). (2da. ed.). Lima: Fondo Editorial Universidad Antonio Ruiz de Montoya.

Díaz, F. y Hernández, G. (2010). Estrategias docentes para un aprendizaje significativo. Una interpretación constructivista. (3ra. ed.). México: McGraw-Hill/ Interamericana.

Elorrieta, F. y Elorrieta, E. (2008). Cusco y el Valle Sagrado de los Incas. (2da. ed.). Perú: Alkamari E.I.R.L. 
Eeckhout, P. (2004). Relatos míticos y prácticas rituales en Pachacamac. Boletín del Instituto Francés de Estudios Andinos, 33(1), 1-54. https://doi.org/10.4000/ bifea. 5786

García, F. (2017). La serpiente: dimensiones de una divinidad subterránea en los andes. En C. Carranza, A. Gutiérrez y H. Medina, La figura de la serpiente en la tradición oral iberoamericana (pp. 14-26). Espańa: Fundación Joaquín Díaz. Recuperado de http://archivos.funjdiaz.net/digitales/actas/ la_figura_de_la_serpiente2017.pdf

Garcilaso, I. (2009). Primera parte de los comentarios reales: que tratan del origen de los yncas, reyes que fvereon del Perv, de sv idolatria, leyes, y gouirono en paz y en guerra: de sus vidas y conquistas, $y$ de todo lo que fue aquel imperio y su repusblica, antes que los españoles passaran a el. (Modernización de la edición de 1609). Edición Princeps. Recuperado de http://shemer.mslib.huji. ac.il/lib/W/ebooks/001531300.pdf

Góngora, M. (2015). Llankay, Yachay y Sonkoy. Valores históricos del pueblo en el Tawantinsuyo. Alma Máter, 2(2), 171-190. Recuperado de http://revistasinvestigacion.unmsm.edu.pe/index.php/alma/article/ download/11895/10616

Gudemos, M. (2005). Capac, Camac, Yacana. El Capac Raymi y la música como emblema de poder. Anales del Museo de América, 13, 9-52. Recuperado de https://dialnet.unirioja.es/descarga/articulo/1429363.pdf

Gudemos, M. (2011). «Pichqa-tawa», sistema de medición andino prehispánico. Anales del Museo de América, 19, 233-257. Recuperado de https://dialnet. unirioja.es/descarga/articulo/4150143.pdf

Guerreira, M. (2004). La planificación de los sistemas educativos en la estrategia política de los Incas. Revista de Ciencias de la Educación: Órgano del Instituto Calasanz de Ciencias de la Educación, (200), 397-420.

Jung, C. (2002). Recuerdos, sueños, pensamientos. Buenos Aires: Seix Barral.

Jung, C. (1985). Tipos psicológicos. Tomo II. Recuperado de https://es.slideshare. net/MarceloArayaGonzlez/tipos-psicolgicos-tomo-ii

Kolb, A. y Kolb, D. (2005). The Kolb Learning Style Inventory - Version 3.12005 Technical Specifications. Boston, MA: Hay Resource Direct, 200, 72.

Lajo, J. (2006). Qhapaq Nan: la ruta inka desabiduría. Recuperado dehttps://digitalrepository.unm.edu/cgi/viewcontent.cgi?article=1357\&context=abya_yala

Laurencich, L. (2003). Nuevas perspectivas sobre los fundamentos ideológicos del Tahuantinsuyu: lo sagrado en el mundo Inca de acuerdo a dos documentos jesuíticos secretos. Espéculo, revista de estudios literarios. Recuperado de http://www.biblioteca.org.ar/libros/152135.pdf 
Macas, L. (2010). El Sumak kawsay. Yachaykuna (Saberes), 13, 13-39. Recuperado de http://icci.nativeweb.org/yachaikuna/Yachaykuna13.pdf

Martínez-Abascal, M. (2001). Las tipologías como antecedentes de la teoría de la personalidad de HJ Eysenck. Revista de Historia de la Psicología, 22(3), 407-414. Recuperado de http://www.revistahistoriapsicologia.es/ app/download/5854777511/17.+MART\%C3\%8DNEZ-ABASCAL. pdf?t=1365027009

Mayta, A. (2012). La Biblia WankaXauxa. Huancayo: Editorial Diario Correo.

Ministerio de Relaciones Exteriores de Bolivia (2009). Aprendiendo nuevos protocolos: El Akhulli. La hoja de coca en la diplomacia de los pueblos. Recuperado de http://www.cancilleria.gob.bo/webmre/sites/default/files/libros/05\%20 aprendiendo\%20nuevos\%20protocolos \%20-\%20el\%20akhulli.pdf

Poma, F. (1980a). Nueva corónica y Buen gobierno. Tomo I. (Modernización de la edición de 1615). Fundación Biblioteca Ayacucho. Recuperado de http:// www.latinamericanstudies.org/incas/Nueva_coronica_1.pdf

Poma, F. (1980b). Nueva corónica y Buen gobierno. Tomo II. (Modernización de la edición de 1615). Fundación Biblioteca Ayacucho. Recuperado de https://www.latinamericanstudies.org/incas/Nueva_coronica_2.pdf

Renés, P. y Martínez, P. (2015). Estilos de enseñanza y aprendizaje. Bilbao, España: Ediciones Mensajero.

Rostworowski, M. (1992). Pachacamac y el Señor de los Milagros. Una trayectoria milenaria. Lima: Instituto de Estudios Peruanos.

Salazar, E. (2014). Astronomía Inka: Arqueoastronomía y Etnoastronomia. (2da. ed.). Lima: Museo Andrés del Castillo.

Tacca, L. (2012). La serpiente en los Andes prehispánicos (imágenes en el valle de Arequipa). Historia, 9, 15-19.

Urton, G. (1981). Animals and astronomy in the Quechua universe. Proceedings of the American Philosophical Society, 125(2), 110-127. Recuperado de http://www.fcaglp.unlp.edu.ar/ sixto/arqueo/curso/Urton $\% 20-\% 20$ Animals\%20and\%20Astronomy\%20in\%20the\%20Quechua $\% 20$ Universe.pdf

Yates, J. (2015). Re-animating Andean worlds: kamayoq, the politics of 'culturally appropriate' knowledge extension, and ethnodevelopment in the Peruvian Andes (doctoral thesis). University of British Columbia, Canadá. https:// doi.org/10.14288/1.0166168

Zull, J. (2002). The Art of changing the brain. Sterling, VA: Stylus Publishing, LLC. 